\title{
Enhanced lakebed sediment erosion in Dongting Lake induced by the operation of the Three Gorges Reservoir
}

\author{
ZHOU Yongqiang ${ }^{1,2,3}$, ' ${ }^{*}$ J Jingbao ${ }^{1}$, ZHANG Yunlin ${ }^{2}$, ZHANG Xinping ${ }^{1}$, LI Xichun ${ }^{4}$ \\ 1. College of Resources and Environmental Sciences, Hunan Normal University, Changsha 410081, China; \\ 2. Nanjing Institute of Geography and Limnology, CAS, Nanjing 210008, China; \\ 3. University of Chinese Academy of Sciences, Beijing 100049, China; \\ 4. Hunan Hydro \& Power Design Institute, Changsha 410007, China
}

\begin{abstract}
Based on field-survey hydrological series in the Dongting Lake watershed from 1951 to 2011, the variations of lakebed sediment siltation/erosion (S/E) regimes of the Dongting Lake after the operation of the Three Gorges Reservoir (TGR) were analyzed. Significantly positive correlations were found between the flow rate from Zhicheng and the Three Outlets $\left(r^{2}=0.859, p<0.0001\right)$, and between the flow rate and sediment delivery rate at the Three Outlets $\left(r^{2}=0.895, p<0.0001\right)$. This indicated that the flow rate and sediment delivery rate at the Three Outlets were largely determined by the flow rate from the upstream Yangtze River. Sediment deposition amount in the Dongting Lake basin dropped from $+4796.4 \times 10^{4} \mathrm{t}$ during the period before the operation of TGR (1999-2002) to $+684.1 \times 10^{4} t,+449.8 \times 10^{4} \mathrm{t}$ and $-559.6 \times 10^{4}$ t during the impoundment Phases I, II and III of TGR. The S/E regimes changed from a siltation-dominant to an erosion-dominant state under the pre-discharge, water-storage and water-supplement dispatch over the impoundment from Phase I to III. The sediment deposition amount decreased dramatically under the flood-storage dispatch over the impoundment Phase I to III. The estimated annual mean flow rate, sediment delivery rate and sediment concentration thresholds were respectively $970.81 \mathrm{~m}^{3} / \mathrm{s}, 466.82 \mathrm{~kg} / \mathrm{s}$ and 0.481 $\mathrm{kg} / \mathrm{m}^{3}$ for the upstream Three Outlets to maintain an erosion-dominant state in the downstream linked the Dongting Lake.
\end{abstract}

Keywords: The Three Outlets; The Three Gorges Reservoir (TGR); flow rate; sediment delivery rate; Dongting Lake

\section{Introduction}

The operation of large-scale water conservancy projects can change the natural hydrological

Received: 2015-02-09 Accepted: 2015-03-20

Foundation: National Natural Science Foundation of China, No.41071067; Program of the Key Discipline Construction of the Physical Geography in Hunan Province

Author: Zhou Yongqiang (1988-), PhD, specialized in unraveling the dynamics of lake ecosystem.

E-mail: yohnchou917251@126.com

*Corresponding author: Li Jingbao (1951-), Professor, E-mail: lijingbao1951@126.com 
cycles and sediment translocation processes in downstream linked lakes, and further result in the adjustment of lakebed shapes (Sharaf El Din, 1977; Keown et al., 1986; Walling, 2006). Yangtze River is known as the largest river in China. The middle Yangtze River has experienced the blocking of Tiaoxian outlet, the Jingjiang truncation and and the river closure of Gezhouba, etc. (Li et al., 2005) over the last 60 years. These anthropogenic activities resulted in the adjustments of the relationships between the Yangtze River and the Dongting Lake (Han, 1999; Xu et al., 2004; Fu et al., 2005). The operation of the Three Gorges Reservoir (TGR) resulted in a deposition of vast amount of sediment in the reservoir. This further resulted in an unsaturated sediment carrying capacity in the downstream linked riverway (He et al., 2006). After the impoundment of TGR, especially under the dispatching mode of water-supplement and water-storage, riverbed sediment erosions happened to the downstream linked Jingjiang River. This implied a potential enhanced lakebed sedment erosion can happen to the downstream linked the Dongting Lake.

The relationship between the Dongting Lake and the Yangtze River and flood damages in the Dongting Lake watershed have been studied by the scholars from different perspectives (Zhang et al., 2010; Lu et al., 1999; Lu et al., 2006; Li et al., 2009; Zhong et al., 2008; Wang et al., 2003; Dai et al., 2005). However, few studies have been concerning on the threshold values of upstream water and sediment regulation to achieve a healthy Dongting Lake. How will the regimes (siltation or erosion, S/E) regarding to the lakebed sediment of the Dongting Lake respond to the operation of TGR remains largely unknown.

Therefore, the primary objective of the study was to characterize the lakebed sediment $\mathrm{S} / \mathrm{E}$ processes of the Dongting Lake after the operation of TGR based on the field-survey hydrological series. By examining the relationships between flow rate and sediment delivery rate of the Three Outlets ${ }^{1}$ and S/E rate in the Dongting Lake, we sought to unravel the threshold values for water and sediment regulation of the upstream TGR to maintain a healthy state of the lake from the perspective of lakebed sediment deposition.

\section{Material and methods}

\subsection{Hydrological data}

Daily inflow and outflow rate of TGR were provided by the Yangtze River hydrological data service system (http://www.ctg.com.cn/inc/sqsk.php\#1643). The daily flow rate of hydrological stations in the Dongting Lake watershed and the middle reaches of the Yangtze River were provided by the Hunan Hydro \& Power Design Institute and the Hunan hydrological data service system (http://www.hnsw.com.cn/tabid/230/Default.aspx). Long-term (19512011) sediment delivery rate were provided by Changjiang (Yangtze) Water Resources Committee and the Hunan Hydro \& Power Design Institute and were well validated by the data in Yangtze River Sediment Bulletin².

\subsection{Analysis method}

Based on the hydrological relationship between TGR and the Dongting Lake, we sought to

\footnotetext{
${ }^{1}$ The Three Outlets refer to the Songzi (Songzikou and Shadaoguan), Taiping (Mituosi) and Ouchi (Kangjiagang and Guanjiapu)

${ }^{2}$ http://www.cjh.com.cn/pages/nsgb.html
} 
unravel the hydraulic connections among the outflow rate of TGR, flow rate at Zhicheng and the Three Outlets. The lakebed sediment S/E rate was estimated by the difference between inflow and outflow sediment delivery rate in the lake. It is noteworthy that the lakebed sediment S/E rate was calculated without considering the inflow sediment dilivery rate from the ungauged regions in the lake watershed. The lakebed sediment S/E regimes of the Dongting Lake were then analyzed. By investigating the correlation between the inflow rate at upstream Three Outlets and S/E rate in the Dongting Lake, the water and sediment regulation thresholds of upstream TGR were estimated.

\section{Hydrological relationship between TGR and Dongting Lake}

Dongting Lake receives water and sediment from the Three Outlets in the south bank of Jingjiang in the middle reach (SJR) of the Yangtze River and the Four Rivers ${ }^{1}$ in the lake watershed and finally discharged them to the Yangtze River at Chenglingji (Figure 1). The normal water level and the corresponding flood control capacity of TGR under the dispatching mode of water-storage are $175 \mathrm{~m}$ and $221.5 \times 10^{8} \mathrm{~m}^{3}$, respectively. The drainage area of TGR is approximately $100 \times 10^{4} \mathrm{~km}^{2}{ }^{2}$. Thus, the flow rate at Zhicheng can be largely controlled by the operation of TGR. Water and sediment are discharged into the Dongting Lake from the Jingjiang reach of the Yangtze River via the Three Outlets. The hydrological processes of the Dongting Lake are therefore closely related to the water and sediment outflow rate from TGR. Significantly positive correlations were found between the outflow rate of TGR and the flow rate at Yichang, and between the flow rate at Yichang and Zhicheng $(p<0.0001)$ (Figure 2). The distances between Huanglingmiao (the hydrological station right at the downstream of TGR) and Yichang, and between Yichang and Zhicheng were 35 and $58 \mathrm{~km}$, respectively. This suggested that after minimizing the time-lag effect, the correlations aforementioned can be better, and further substantiated that the flow rate at Zhicheng has been directly controlled by the outflw rate of TGR.

Significantly positive relationship was found between the flow rate at the Three Outlets and the flow rate at Zhicheng $(p<0.0001$, Figure 3 ). The multi-year annual mean sediment discharge from the Three Outlets before the operation of TGR could be up to $14125.48 \times 10^{4} \mathrm{t}$ and contributed a percentage of $81.53 \%$ of the total inflow sediment discharge amount to the Dongting Lake. The cor-

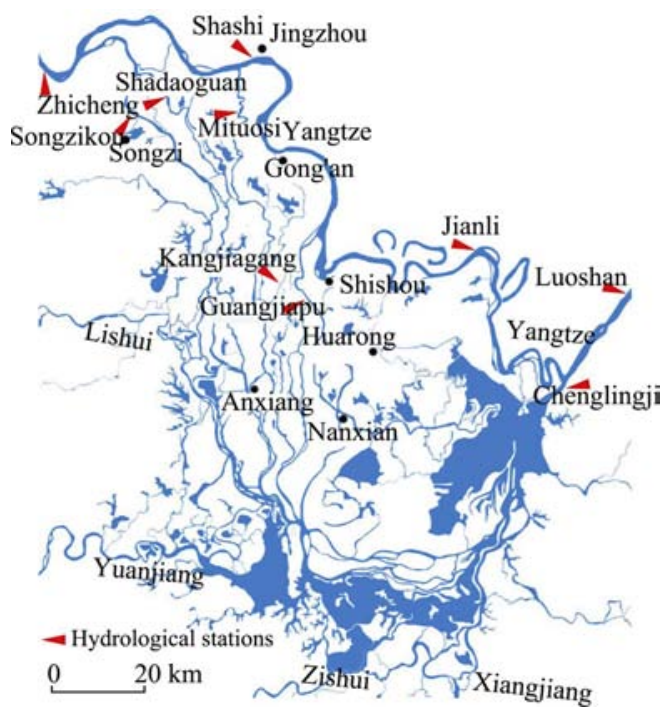

Figure 1 Locations of hydrological stations in the Dongting Lake watershed

\footnotetext{
1 The Four Rivers indicate the four major rivers in the Dongting Lake watershed, including rivers of Xiangjiang, Zishui, Yuanjiang and Lishui.

2 "Report on the River-Lake Relationship and Flood Control in the Middle and Lower Reaches of Yangtze River". (Edited by Changjiang (Yangtze) Water Resources Committee, 2006)
} 
responding annual mean inflow sediment discharge from the Four Rivers was $3198.31 \times 10^{4} \mathrm{t}$ and was relatively stable. This indicated that the lakebed sediment S/E amount can be largely determined by the inflow sediment discharge from the upstream Three Outlets. Close relationship was found between the flow rate and sediment delivery rate from the Three Outlets $(p<0.0001$, Figure 3$)$. This implied that the sediment delivery rate from the Three Outlets can be largely determined by the corresponding flow rate.
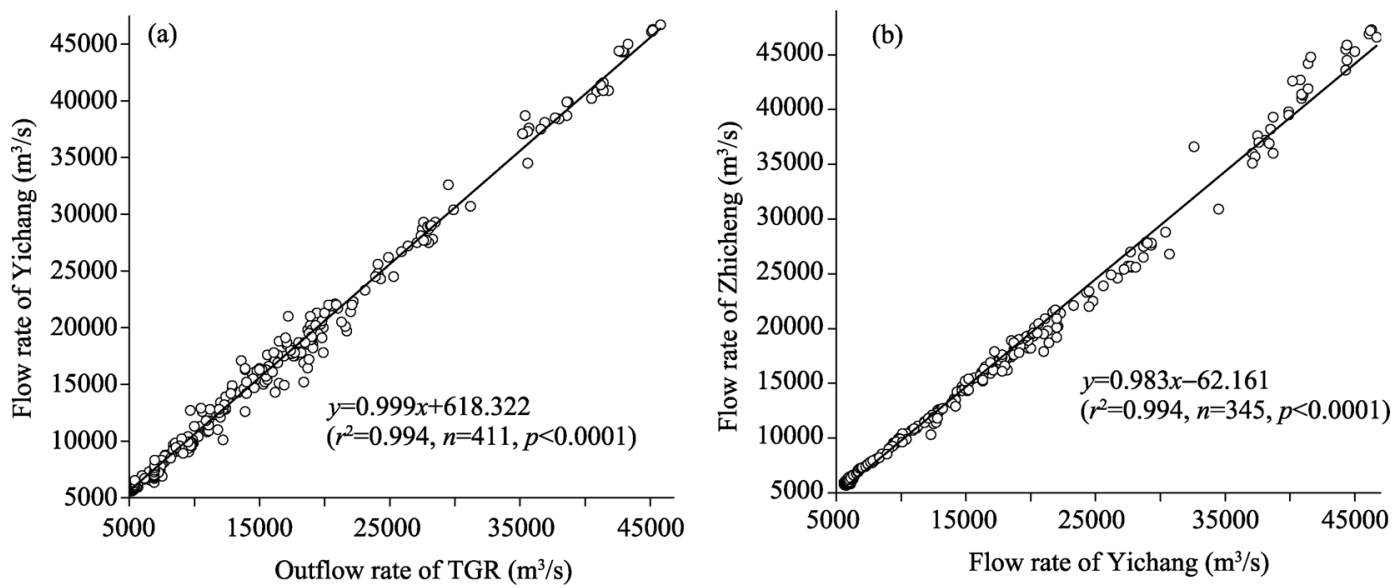

Figure 2 Relationships between the flow rate at Yichang and the outflow rate from the Three Gorges Reservoir (a) and between the flow rate at Yichang and Zhicheng (b)
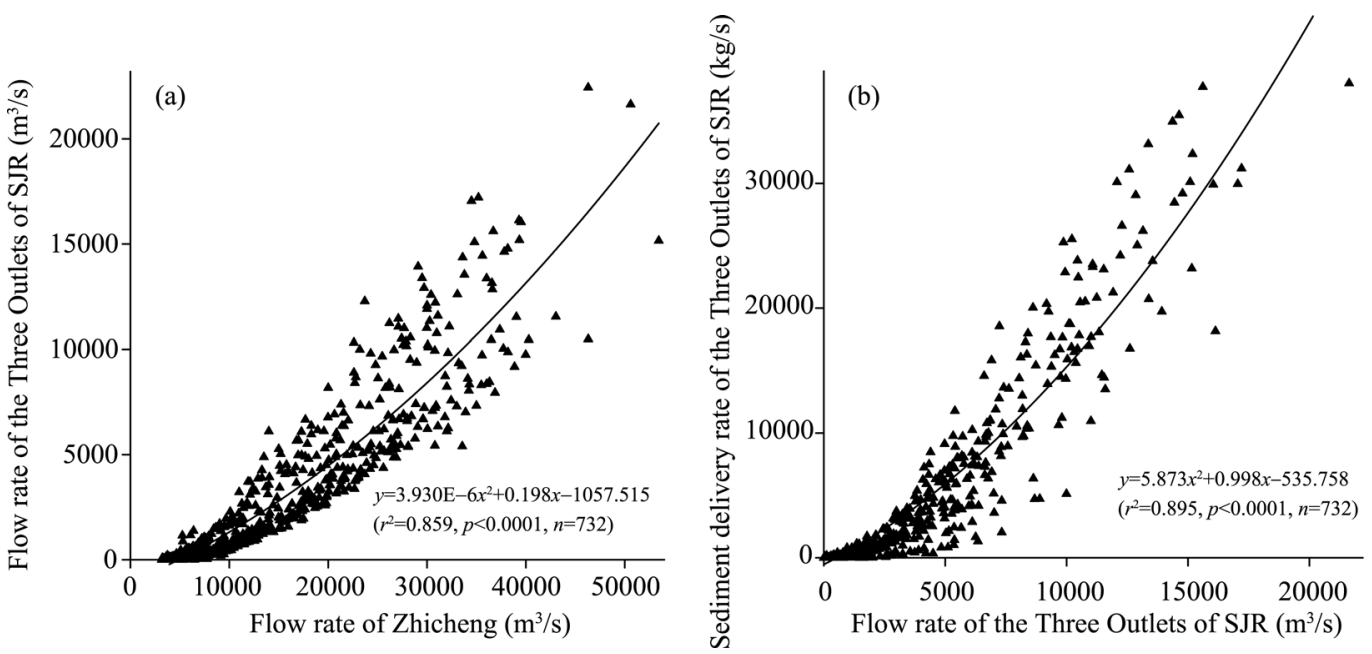

Figure 3 Relationships between the flow rate at Zhicheng and at the Three Outlets (a) and between the flow rate and sediment delivery rate at the Three Outlets (b)

The runoff and sediment discharge from the Three Outlets and lakebed sediment deposition amount in the Dongting Lake exhibited similar patterns over the last 60 years, with the abundances showed wavelike decrease changes (Figure 4). After the impoundment of TGR, the sediment discharge from the Three Outlets and lakebed sediment deposition amount in the Dongting Lake displayed notable decrease trends. The lakebed sediment S/E regimes changed from a siltation-dominant state to an erosion-dominant state during the period. This 
further suggested a dramatic change has probably happened to the Yangtze River-Dongting Lake (River-Lake) system after the impoundment of TGR.

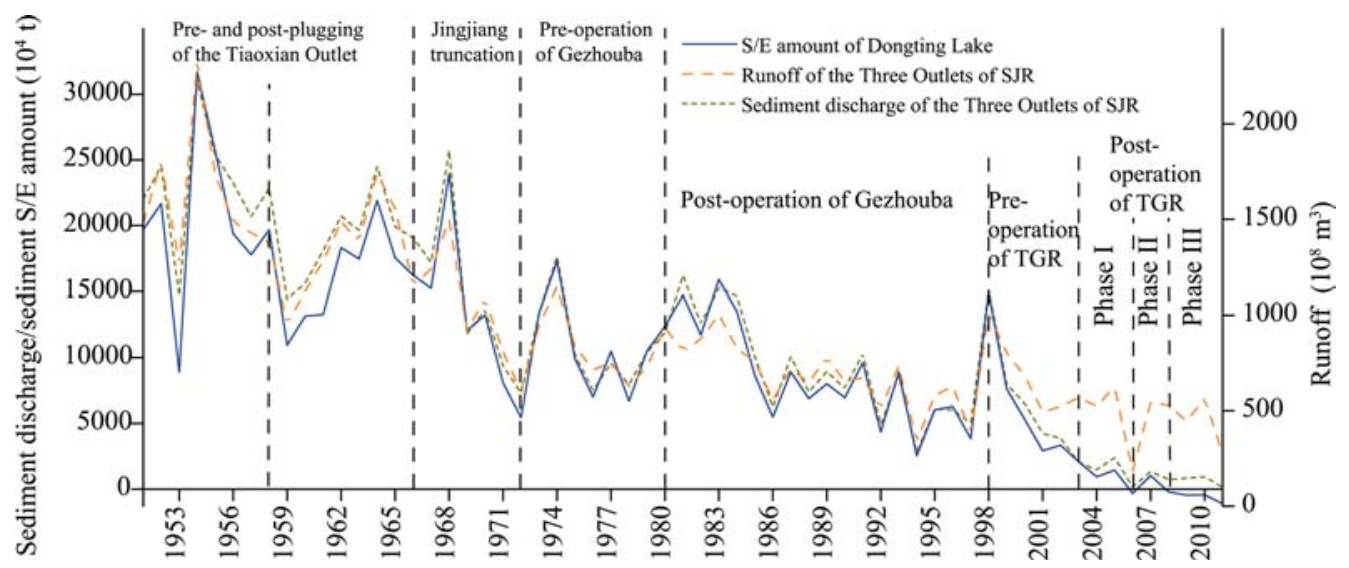

Figure 4 Variations of runoff and sediment discharge from the Three Outlets and sediment S/E amount of the Dongting Lake in different periods of time

\section{Variation of lakebed sediment S/E regimes before the operation of TGR}

In order to elucidate the lakebed sediment S/E characteristics in the Dongting Lake after the impoundment of TGR, the period before the operation of TGR (1951-2002) is divided into the following six phases (Li et al., 2009). The pre- (1951-1958) and post- (1959-1966) plugging of the Tiaoxian Outlet, the Jingjiang truncation (1967-1972), the pre-operation of Gezhouba (1973-1980), the post-operation of Gezhouba (1981-1998) and the pre-operation of TGR (1999-2002).

To investigate the interannual variation of lakebed sediment S/E regimes of the Dongting Lake, the mean inflow runoff and sediment discharge to the lake during the period of pre-plugging of the Tiaoxian Outlet (1951-1958) was used as reference. The annual mean inflow runoff and sediment discharge from the Three Outlets decreased respectively by $277.1 \times 10^{8} \mathrm{~m}^{3}, 587.7 \times 10^{8} \mathrm{~m}^{3}, 776.1 \times 10^{8} \mathrm{~m}^{3}, 918.2 \times 10^{8} \mathrm{~m}^{3}, 987.7 \times 10^{8} \mathrm{~m}^{3}$ and $4053.3 \times 10^{4} \mathrm{t}$, $8867.6 \times 10^{4} \mathrm{t}, 11965.8 \times 10^{4} \mathrm{t}, 13700.9 \times 10^{4} \mathrm{t}, 17385.7 \times 10^{4} \mathrm{t}$ during the periods of 1959-1966, 1967-1972, 1973-1980, 1981-1998 and 1999-2002 (Table 1). The corresponding decreasing amplitudes were $17.18 \%, 36.44 \%, 48.13 \%$, 56.94\%, $61.25 \%$ and $17.59 \%$, 38.49\%, $51.93 \%, 59.46 \%, 75.45 \%$, respectively. This further substantiated that the sediment discharge from the Three Outlets was controlled by the corresponding runoff amount. The annual runoff of the Four Rivers varied slightly (-11.77\% to $4.35 \%)$ during the six aforementioned periods. Notable decrease trends were observed for the mean inflow runoff and sediment discharge to the lake. It is noteworthy that the annual mean inflow runoff to the lake increased from $2713.3 \times 10^{8} \mathrm{~m}^{3}$ to $2815.5 \times 10^{8} \mathrm{~m}^{3}$ whereas the annual sediment discharge decreased from $11687.9 \times 10^{4}$ t to $6827.2 \times 10^{4} \mathrm{t}$. This can be explained by the Jingjiang truncation and the Yangtze River closure at Gezhouba. The decreased inflow runoff and sediment discharge to the Dongting Lake over the six periods resulted in a decreased outflow runoff and sediment discharge from the Dongting Lake to the Yangtze River at Chenglingji. 
The outflow sediment discharge decreased by 13.66\%, 21.72\%, 42.86\%, 55.94 and 69.69\% over the periods of 1959-1966, 1967-1972, 1973-1980, 1981-1998 and 1999-2002. It is notable that the outflow sediment discharge was much lower than the inflow amount during the corresponding period. This indicated a large amount of sediment was deposited in the lake over the last 60 years.

Table 1 Variations of annual mean runoff $\left(10^{8} \mathrm{~m}^{3}\right)$, sediment discharge and deposited $\left(10^{4} \mathrm{t}\right)$ and corresponding deposition rate (\%) in the Dongting Lake during the time periods before the operation of the Three Gorges Reservoir. The Three Outlets: TO; The Four Rivers: FR; Ungauged region: UGR

\begin{tabular}{|c|c|c|c|c|c|c|c|c|c|c|}
\hline \multirow{2}{*}{ Period } & \multicolumn{4}{|c|}{ Annual mean inflow runoff } & \multicolumn{3}{|c|}{ Inflow sediment discharge } & \multirow{2}{*}{$\begin{array}{l}\text { Outflow } \\
\text { sediment } \\
\text { discharge }\end{array}$} & \multirow{2}{*}{$\begin{array}{c}\text { Sediment } \\
\text { deposited } \\
\text { amount }\end{array}$} & \multirow{2}{*}{$\begin{array}{c}\text { Sediment } \\
\text { deposition } \\
\text { rate }\end{array}$} \\
\hline & TO & FR & UGR & The sum & TO & FR & The sum & & & \\
\hline 1951-1958 & 1612.6 & 1741.9 & 299.1 & 3653.6 & 23041.6 & 4230.6 & 27272.2 & 6715.7 & 20556.5 & 75.38 \\
\hline 1959-1966 & 1335.5 & 1536.9 & 225.8 & 3098.2 & 18988.3 & 2905.7 & 21894.0 & 5786.0 & 16108.0 & 73.57 \\
\hline 1967-1972 & 1024.9 & 1727.9 & 255.3 & 3008.1 & 14174.0 & 4080.0 & 18254.0 & 5246.0 & 13008.0 & 71.26 \\
\hline 1973-1980 & 836.5 & 1698.9 & 256.2 & 2791.6 & 11075.8 & 3712.5 & 14788.3 & 3828.8 & 10959.5 & 74.11 \\
\hline 1981-1998 & 694.4 & 1702.9 & 316.0 & 2713.3 & 9340.7 & 2347.2 & 11687.9 & 2952.8 & 8735.1 & 74.74 \\
\hline 1999-2002 & 624.9 & 1817.7 & 372.9 & 2815.5 & 5655.9 & 1171.3 & 6827.2 & 2030.8 & 4796.4 & 70.25 \\
\hline
\end{tabular}

Based on the Law of Conservation of Mass that the lakebed sediment S/E amount in the Dongting Lake is estimated by subtracting the outflow from the inflow sediment discharge to the lake, we can arrive at following a few rational conclusions. (1) During the flood season (May to October) of the lake watershed, flood surged into the lake accompanied by the block effect at Chenglingji induced by the high water level in the main stream of the Yangtze River (Duan et al., 2001), vast amount of sediment were deposited to the lakebed. Due to the decreasing inflow sediment discharge of the Three Outlets, the lakebed sediment deposition amount decreased by 5.36\%, 36.47\%, 48.01\%, 57.60\% and $75.60 \%$ during the periods of 1959-1966, 1967-1972, 1973-1980, 1981-1998 and 1999-2002 compared to that in 1951-1958. (2) In the low water season (January to April and November to December), the unsaturated sediment carrying capacity in the riverway resulted in a lakebed sediment erosion (Table 2). During the period of 1999-2002, the intra-annual erosion state prelonged from April to May. Similar to the lakebed sediment deposition amount in the lake, the erosion amount during the corresponding period decreased by $7.07 \%, 23.35 \%, 55.32 \%, 52.76 \%$ and $60.31 \%$, respectively (Table 2). This can be explained by a decreased water level at the Three Outlets resulted from large-scale water conservancy projects in the main stream of the

Table 2 Variations of monthly mean sediment S/E amount $\left(10^{4} \mathrm{t}\right)$ in the Dongting Lake during the time periods before the operation of TGR. Depo: Deposition amount; Eros: Erosion amount

\begin{tabular}{ccccccccccccccc}
\hline Time (yr) & Jan & Feb & Mar & Apr & May & Jun & Jul & Aug & Sep & Oct & Nov & Dec & Dep & Ero \\
\hline $1951-1958$ & -132 & -183 & -351 & -487 & 565 & 2496 & 8183 & 7556 & 2731 & 507 & -93 & -219 & 22545 & -1683 \\
$1959-1966$ & -124 & -211 & -384 & -409 & 449 & 1671 & 5806 & 5284 & 3619 & 888 & -184 & -252 & 21337 & -1564 \\
$1967-1972$ & -115 & -134 & -327 & -405 & 861 & 1872 & 5364 & 3077 & 2450 & 700 & -145 & -163 & 14323 & -1290 \\
$1973-1980$ & -40 & -125 & -185 & -243 & 389 & 2017 & 3566 & 2945 & 2231 & 574 & -78 & -81 & 11722 & -752 \\
$1981-1998$ & -83 & -134 & -211 & -201 & 87 & 1041 & 4078 & 2519 & 1570 & 263 & -87 & -79 & 9558 & -795 \\
$1999-2002$ & -60 & -48 & -150 & -204 & -23 & 754 & 2095 & 1504 & 995 & 151 & -106 & -78 & 5500 & -668 \\
\hline
\end{tabular}


middle reach of the Yangtze River.

\section{Variation of lakebed sediment S/E regimes after the operation of TGR}

\subsection{Differentiating the phases and dispatching modes of the operation of TGR}

The operation of TGR began in May 2003, and the water level of the reservoir rose up to $135 \mathrm{~m}$ in June 2003. In October 2006, water level of the reservoir rose up to $156 \mathrm{~m}$, flood control water level in 2008 was $145 \mathrm{~m}$ and water level during the non-flood season rose up to $172.8 \mathrm{~m}$ in October 2008. It increased to $175 \mathrm{~m}$ during the non-flood period in $2010^{1}$. This indicated that the impoundment of TGR (June 2003 to December 2011) can be divided into the following three different phases. Phase I, period of cofferdam (June 2003 to September 2006). Phase II, the preliminary operation period of TGR (October 2006 to September 2008). Phase III, the official launching period (October 2008 to December 2011).

The runoff in the middle and lower reaches of the Yangtze River has changed dramatically since the operation of TGR, the hydrological year of the middle reaches of the Yangtze River after the operation of TGR (2003 to 2011) was therefore determined. The level of high or low water season in the middle reaches of the Yangtze River was estimated according to the Hydrological Forecast Specification edited by the Ministry of Water Resources of China:

$$
P(\%)=\frac{\text { Runoff in } t^{\text {th }} \text { month-Multi-year mean monthly runoff }}{\text { Multi-year mean monthly runoff }} \times 100 \%
$$

where the time period is wet if $P>20 \%$; if $10 \%<P \leqslant 20 \%$, the time period is wet-like; if $-10 \%<P \leqslant 10 \%$, the time period is normal; if $-20 \%<P \leqslant-10 \%$, the time period is dry-like; if $P \leqslant-20 \%$, the time period is dry. The runoff departure of the middle reaches of the Yangtze River is calculated base on the runoff at the hydrological station Zhicheng (Table 3).

Table 3 Departures of runoff in the middle and lower reaches of the Yangtze River during different water impoundment phases of TGR

\begin{tabular}{cccccccccccc}
\hline Phase & \multicolumn{3}{c}{ Phase I } & \multicolumn{4}{c}{ Phase II } & \multicolumn{3}{c}{ Phase III } \\
\hline Time & $2003.6-12$ & 2004 & 2005 & $2006.1-9$ & $2006.10-12$ & 2007 & $2008.1-9$ & $2008.10-12$ & 2009 & 2010 & 2011 \\
Depar & +14.04 & +5.54 & +13.52 & -29.19 & -18.12 & +7.00 & +3.29 & +16.40 & +0.92 & +2.69 & -17.29 \\
\hline
\end{tabular}

According to the optimization scheduling solution of TGR aforementioned, TGR is under the pre-discharge dispatch during May to June. Water level of TGR during this time period decreased from 155 to $145 \mathrm{~m}$, and the corresponding flow rate in the downstream riverway increased by $3800 \mathrm{~m}^{3} / \mathrm{s}$. The flood-storage dispatch of TGR occurs in July to August, and water level of TGR is lowered down to $145 \mathrm{~m}$. During September to October, TGR is under the water-storage dispatch, and the water level of the reservoir increased from 145 to $175 \mathrm{~m}$, and the corresponding outflow rate decreased by $5500 \mathrm{~m}^{3} / \mathrm{s}$. The water-supplement dispatch of TGR occurs during the time period ranging from December to April, when the water level of the reservoir decreased from 175 to $155 \mathrm{~m}$, the corresponding outflow rate of TGR increased by $1000-2000 \mathrm{~m}^{3} / \mathrm{s}$ (Li et al., 2011). The lakebed sediment S/E rate will be influ-

1 “The Optimization Scheduling Solution of TGR” (Edited by Changjiang (Yangtze) Water Resources Committee, 2009) 
enced by both the impoundment phase and the dispatching mode of TGR.

\subsection{Variation of lakebed sediment S/E regimes under different impoundment phases of TGR}

During the impoundment Phase I of TGR (June 2003 to September 2006), water level of the reservoir during flood season was $135.5 \mathrm{~m}$, and increased to $139 \mathrm{~m}$ during the non-flood season ${ }^{1}$. Compared with the time period of 1999 to 2002, the multi-year mean annual inflow runoff and sediment discharge from the Three Outlets decreased respectively by $180.6 \times 10^{8}$ $\mathrm{m}^{3}$ and $4318.7 \times 10^{4} \mathrm{t}$. Simultaneously, the annual inflow runoff and sediment discharge from the Four Rivers decreased by $296.2 \times 10^{8} \mathrm{~m}^{3}$ and $310.8 \times 10^{4} \mathrm{t}$, respectively. The outflow runoff from Dongting Lake at Chenglingji decreased by $25.47 \%$ during the corresponding time period, and could be explained by a decreased inflow runoff and hence with lower sediment carrying capacity compared to 1999 to 2002.

The lakebed sediment deposited in Dongting Lake mainly comes from the Yangtze River via the Three Outlets. The annual lakebed sediment deposition amount in the Dongting Lake decreased by $4112.3 \times 10^{4} \mathrm{t}$ compared to that in the period 1999-2002 (Table 4). This indicated that although the lakebed sediment $\mathrm{S} / \mathrm{E}$ regimes were still dominate by deposition, the rate in the impoundment Phase I of TGR was lowered down dramatically compared to that

Table 4 Variations of annual mean runoff $\left(10^{8} \mathrm{~m}^{3}\right)$, sediment discharge and deposited $\left(10^{4} \mathrm{t}\right)$ and corresponding deposition rate (\%) in Dongting Lake during different impoundment phases of the Three Gorges Reservoir. The Three Outlets: TO; The Four Rivers: FR; Ungauged region: UGR, *: Impoundment Phase I; **: Phase II; ***: Phase III; “+”: deposition; “-”: erosion

\begin{tabular}{|c|c|c|c|c|c|c|c|c|c|c|}
\hline \multirow{2}{*}{$\begin{array}{l}\text { Time } \\
\text { (yr) }\end{array}$} & \multicolumn{4}{|c|}{ Annual mean inflow runoff } & \multicolumn{3}{|c|}{ Inflow sediment discharge } & \multirow{2}{*}{$\begin{array}{c}\text { Outflow } \\
\text { sediment } \\
\text { discharge }\end{array}$} & \multirow{2}{*}{$\begin{array}{c}\text { Sediment } \\
\text { deposited } \\
\text { amount }\end{array}$} & \multirow{2}{*}{$\begin{array}{c}\text { Sediment } \\
\text { deposition } \\
\text { rate }\end{array}$} \\
\hline & TO & FR & UGR & The sum & TO & FR & The sum & & & \\
\hline 1999-2002 & 624.9 & 1817.7 & 372.9 & 2815.5 & 5655.9 & 1171.3 & 6827.2 & 2030.8 & +4796.6 & +70.25 \\
\hline 2003.06-12* & 551.5 & 724.4 & 155.8 & 1449.7 & 2020.9 & 1374.5 & 3415.4 & 716.8 & +2698.6 & +79.01 \\
\hline $2004 *$ & 524.7 & 1499.4 & 306.0 & 2330.1 & 1448.0 & 914.6 & 2362.6 & 1429.9 & +932.7 & +39.48 \\
\hline $2005^{*}$ & 625.6 & 1510.8 & 261.0 & 2397.4 & 2401.6 & 640.1 & 3041.7 & 1593.5 & +1448.2 & +47.61 \\
\hline 2006.01-09* & 166.5 & 1385.0 & 184.5 & 1736.0 & 162.0 & 1011.0 & 1173.0 & 1400.7 & -227.7 & -19.41 \\
\hline 2003.06-2006.09 & 444.3 & 1521.5 & 258.0 & 2223.8 & 1337.2 & 860.5 & 2197.7 & 1513.5 & +684.1 & +31.10 \\
\hline $2006.10-12^{* *}$ & 16.1 & 169.3 & 22.6 & 208.0 & 0.0 & 15.7 & 15.7 & 116.5 & -100.8 & -642.04 \\
\hline $2007 * *$ & 543.6 & 1404.8 & 207.9 & 2156.3 & 1331.4 & 815.4 & 2146.8 & 1118.2 & +1028.6 & +47.91 \\
\hline $2008.01-09 * *$ & 456.0 & 1183.2 & 166.7 & 1805.9 & 727.4 & 656.7 & 1384.1 & 1191.0 & +193.1 & +13.95 \\
\hline 2006.10-2008.09 & 418.3 & 1490.7 & 209.4 & 2118.4 & 1031.8 & 877.4 & 1909.1 & 1459.3 & +449.8 & +23.60 \\
\hline $2008.10-12^{* * *}$ & 72.8 & 329.8 & 46.4 & 449.0 & 4.7 & 133.3 & 138.0 & 551.5 & -413.5 & -299.64 \\
\hline $2009 * * *$ & 445.3 & 1346.6 & 228.1 & 2020.0 & 827.3 & 373.0 & 12003 & 1665.3 & -465.0 & -38.74 \\
\hline $2010 * * *$ & 566.2 & 1817.5 & 325.0 & 2708.7 & 928 & 1249.3 & 2177.3 & 2620.0 & -442.7 & -20.33 \\
\hline $2011^{* * *}$ & 276.2 & 1027.5 & 221.1 & 1524.8 & 148.4 & 201.2 & 349.6 & 1460.0 & -1110.4 & -371.61 \\
\hline 2008.10-2011.12 & 454.1 & 1426.2 & 246.8 & 2127.1 & 659.0 & 653.4 & 1312.3 & 1871.9 & -559.6 & -42.64 \\
\hline 2003.06-2011.12 & 461.6 & 1459.2 & 246.2 & 2167.0 & 997.4 & 751.3 & 1748.6 & 1643.3 & +105.3 & +6.02 \\
\hline
\end{tabular}

1 “The Optimization Scheduling Solution of TGR” (Edited by Changjiang (Yangtze) Water Resources Committee, 2009) 
deposition in 1999 to 2002. It is notable that the lakebed sediment erosion amount was higher than corresponding deposition amount during January to September 2006. The erosion amount can be up to $227.7 \times 10^{4} \mathrm{t}$ during the time period. We assume that the mean bulk weight of lakebed sediment and the lake surface area are respectively $1.3 \mathrm{t} / \mathrm{m}^{3}$ and $2625 \mathrm{~km}$ 1 , and the scouring depth during the time period can be estimated as $0.067 \mathrm{~m}$. This indicated that despite the dry hydrological condition during the time period, the positive effects of TGR on lakebed sediment erosion in Dongting Lake were notable.

During the impoundment Phase II of TGR (October 2006 to September 2008), water level of the reservoir increased from $145 \mathrm{~m}$ during rainy period to $156 \mathrm{~m}$ during dry period, and the corresponding flood storage capacity can be up to $110.8 \times 10^{8} \mathrm{~m}^{32}$. The multi-year mean annual inflow runoff to the Dongting Lake during the impoundment phase decreased respectively by $206.6 \times 10^{8} \mathrm{~m}^{3}$ and $26.0 \times 10^{8} \mathrm{~m}^{3}$ compared with the time period $1999-2002$ and the impoundment Phase I. Similarly, the annual mean runoff of the Four Rivers decreased by $327.0 \times 10^{8} \mathrm{~m}^{3}$ and $30.8 \times 10^{8} \mathrm{~m}^{3}$ respectively compared with the time period 1999-2002 and the impoundment Phase I. This can be explained by the drought in South China during the time period (Chen, 2010). Correspondingly, the sediment discharge of the Three Outlets during the phase decreased by $4624.2 \times 10^{4} \mathrm{t}$ and $305.5 \times 10^{4} \mathrm{t}$ and the sediment discharge of the Four Rivers varied by $-293.9 \times 10^{4} \mathrm{t}$ and $+16.9 \times 10^{4} \mathrm{t}$ (where "+" and "-” indicate deposition and erosion, respectively) compared to the two aforementioned periods. The outflow sediment discharge from the Dongting Lake at Chenglingji varied slightly compared to the two aforementioned time periods. This resulted in an annual mean sediment deposition amount of $449.8 \times 10^{4} \mathrm{t}$ in the lake during this impoundment phase. The deposition amount during the time period decreased by $4346.6 \times 10^{4} \mathrm{t}$ and $234.3 \times 10^{4} \mathrm{t}$ compared to the two aforementioned time periods. It is notable that the lakebed sediment erosion amount was for the first time higher than the deposition amount during the time period of October to December 2006. This was largely associated with the drought in the Yangtze River watershed during the time period $(P=-18.12 \%)$, and runoff at Zhicheng and the Three Outlets during the time period was only $586.4 \times 10^{8} \mathrm{~m}^{3}$ and $16.1 \times 10^{8} \mathrm{~m}^{3}$, respectively. The number of the flow-break days at Shadaoguan, Mituosi, Kangjiagang and Guanjiapu in 2006 were respectively 269, 206, 235 and 336. This further substantiated that the lakebed sediment S/E regimes in Dongting Lake can be largely controlled by upstream hydrological conditions.

The impoundment Phase III of TGR occurred in October 2008 to December 2011. The water level of the reservoir increased from $145 \mathrm{~m}$ in flood season to $175 \mathrm{~m}$ in non-flood season during this phase. The multi-year mean annual runoff from the Three Outlets varied by $-170.8 \times 10^{8} \mathrm{~m}^{3},+9.8 \times 10^{8} \mathrm{~m}^{3}$ and $+35.8 \times 10^{8} \mathrm{~m}^{3}$ (where “+" and "-" denote increase and decrease, respectively) compared to the period 1999-2002 and the impoundment Phases I and II. Correspondingly, the sediment discharge from the Three Outlets decreased by $4997.0 \times 10^{4} \mathrm{t}, 678.2 \times 10^{4} \mathrm{t}$ and $372.8 \times 10^{4} \mathrm{t}$, respectively, compared to the three aforementioned periods. This exhibited the significance of TGR operation in reducing the lakebed sediment deposition amount in the downstream linked Dongting Lake during the impound-

\footnotetext{
1 “The Synthetic Layout Report in the Dongting Lake Area” (Edited by Changjiang (Yangtze) Water Resources Committee, 2010).

2 "Report on the River-Lake Relationship and Flood Control in the Middle and Lower Reaches of Yangtze River". (Edited by Changjiang (Yangtze) Water Resources Committee, 2006)
} 
ment Phase III. The annual inflow runoff from the Four Rivers during the time period decreased by $21.54 \%, 6.27 \%$ and $4.33 \%$ compared to the three aforementioned periods. Correspondingly, the sediment discharge from Dongting Lake at Chenglingji varied respectively by $-158.9 \times 10^{4} \mathrm{t},+358.4 \times 10^{4} \mathrm{t}$ and $+412.6 \times 10^{4} \mathrm{t}$ compared to the three aforementioned periods. This resulted in a total sediment erosion amount higher than the erosion amount in the lake during this impoundment phase and the annual mean sediment erosion amount in the lake can be up to $559.6 \times 10^{4}$ t. The years 2009 and 2010 were both normal flow year in the middle reaches of the Yangtze River and lakebed sediment erosion amount in the two years can be respectively up to $465.0 \times 10^{4} \mathrm{t}$ and $442.7 \times 10^{4} \mathrm{t}$. This implied that compared with the impoundment Phase II, the impoundment Phase III exhibited a better capability in reducing the sediment deposition amount in the lake.

\subsection{Variation of lakebed sediment S/E regimes under different dispatching modes}

The lakebed sediment S/E regimes transformed from a siltation-dominant to an erosion-dominant state under the pre-discharge dispatch (May to June) of TGR (Table 5). The mean sediment erosion amounts in May of the impoundment Phases I, II and III were respectively $65.7 \times 10^{4} \mathrm{t}, 71.5 \times 10^{4} \mathrm{t}$ and $147.0 \times 10^{4} \mathrm{t}$. The corresponding sediment S/E amounts in June of the aforementioned three impoundment phases were respectively $+172.8 \times 10^{4} \mathrm{t}$, $+77.5 \times 10^{4} \mathrm{t}$ and $-84.4 \times 10^{4} \mathrm{t}$. The sediment $\mathrm{S} / \mathrm{E}$ regimes were dominated by siltation under the flood-storage dispatch (July to August). The sediment deposition amount under this dispatch decreased from $1082.0 \times 10^{4} \mathrm{t}$ in impoundment Phase I to $838.0 \times 10^{4} \mathrm{t}$ in Phase II and further to $507 \times 10^{4} \mathrm{t}$ in Phase III. During the water-storage dispatch (September to October), the sediment S/E amount varied from $+396.0 \times 10^{4} \mathrm{t}$ in Phase I to $+49.5 \times 10^{4} \mathrm{t}$ in Phase II and further to $-143.8 \times 10^{4} \mathrm{t}$ in Phase III. Similar to the pre-discharge dispatch, the S/E regimes

Table 5 Variations of monthly mean sediment S/E amount $\left(10^{4} \mathrm{t}\right)$ in Dongting Lake during different impoundment phases of the Three Gorges Reservoir. Depo: Deposition amount; Eros: Erosion amount; “+”: deposition; “-”: erosion

\begin{tabular}{ccccccccccccccc}
\hline Time (yr) & Jan & Feb & Mar & Apr & May & Jun & Jul & Aug & Sep & Oct & Nov & Dec & Depo & Eros \\
\hline $1999-2002$ & -60 & -48 & -150 & -204 & -23 & +754 & +2095 & +1504 & +995 & +151 & -106 & -78 & +5500 & -668 \\
2003 & -93 & -127 & -145 & -160 & -94 & +333 & +1752 & +79 & +649 & -69 & -26 & -18 & +2813 & -734 \\
2004 & -18 & -22 & -171 & -76 & -79 & +119 & +430 & +38 & +844 & -49 & -51 & -27 & +1432 & -493 \\
2005 & -52 & -325 & -100 & -68 & -28 & +154 & +582 & +1137 & +248 & +16 & -84 & -29 & +2137 & -687 \\
2006 & -55 & -56 & -193 & -202 & -90 & +85 & +397 & -87 & -21 & -28 & -33 & -40 & +482 & -805 \\
Phase I & -42 & -134 & -155 & -115 & -66 & +173 & +790 & +292 & +430 & -34 & -54 & -25 & +1685 & -624 \\
2007 & -47 & -39 & -102 & -33 & -64 & +124 & +558 & +646 & +108 & -56 & -25 & -28 & +1437 & -394 \\
2008 & -33 & -28 & -128 & -109 & -79 & +31 & +70 & +402 & +75 & -98 & -257 & -58 & +577 & -790 \\
Phase II & -40 & -34 & -115 & -71 & -72 & +78 & +314 & +524 & +92 & -42 & -29 & -34 & +1007 & -436 \\
2009 & -38 & -66 & -330 & -258 & -194 & -101 & +160 & +550 & -41 & -42 & -49 & -54 & +710 & -1172 \\
2010 & -78 & -35 & -81 & -526 & -157 & +51 & +726 & +162 & +5 & -247 & -62 & -163 & +944 & -1340 \\
2011 & -106 & -68 & -159 & -85 & -89 & -203 & +1 & -78 & -34 & -95 & -91 & -98 & +1 & -1109 \\
Phase III & -74 & -56 & -190 & -287 & -147 & -84 & +296 & +211 & -23 & -121 & -115 & -93 & +507 & -1191 \\
Average & -53 & -80 & -158 & -168 & -98 & +66 & +520 & +317 & +204 & -74 & -75 & -57 & +1106 & -764 \\
\hline
\end{tabular}


under the water-supplement dispatch (December to April) were dominated by erosion. The sediment erosion amount under this dispatch in the aforementioned three phases was respectively $470.7 \times 10^{4} \mathrm{t}, 293.5 \times 10^{4} \mathrm{t}$ and $700.8 \times 10^{4} \mathrm{t}$. This indicated that the lakebed sediment deposition amount decreased dramatically and the intra-annual erosion period prolonged from the impoundment Phase I to Phase III.

\section{Thresholds for water and sediment regulation of upstream TGR}

The regulation and storage capacity of natural lake ecosystems should be maintained at a certain level to achieve a healthy state from the perspective of lakebed sediment deposition. The capacity was especially important in terms of catastrophic flood or long-term drought. Furthermore, the capacity needs to be controlled under the level of self-regulation capability of the River-Lake ecosystem to avoid an excessive anthropogenic interference (He et al., 2006). The multi-year mean inflow sediment discharge to the Dongting Lake from the Three Outlets could account for $80 \%$ of the total inflow sediment amount. Significantly positive correlation was found between the monthly mean lakebed sediment S/E rate and the monthly mean inflow rate of the Three Outlets $\left(r^{2}=0.87, p<0.0001\right.$, Figure 5$)$. By investigating the regression function, and the threshold for the inflow rate from the Three Outlets was estimated as $970.81 \mathrm{~m}^{3} / \mathrm{s}$. Similarly, significant and positive correlation was found between the monthly mean lakebed sediment S/E rate and the monthly mean inflow sediment delivery rate from the Three Outlets $\left(r^{2}=0.973, p<0.0001\right)$. The threshold for the inflow sediment delivery rate from the Three Outlets was estimated as $466.82 \mathrm{~kg} / \mathrm{s}$ based on the correlation function. The thresholds were transformed into sediment concentration (Hu and Zhang, 2006) by dividing the threshold of sediment delivery rate by the flow rate, and the threshold of sediment concentration at the upstream Three Outlets was estimated as $0.481 \mathrm{~kg} / \mathrm{m}^{3}$.

The River-Lake relationship changed dramatically after the operation of TGR and the resulted variation of the lakebed sediment S/E regimes in the Dongting Lake. We used the hydrological series from June 2003 to December 2011 to validate the thresholds estimated. It is notable that the lakebed sediment $\mathrm{S} / \mathrm{E}$ regimes were dominated by erosion when the inflow rate and sediment delivery rate from the Three Outlets were respectively lower than $970.81 \mathrm{~m}^{3} / \mathrm{s}$ and $466.82 \mathrm{~kg} / \mathrm{s}$ (Figure 6). This indicated that the thresholds derived were relatively robust and were relatively straightforward for operation. For example, the mean daily inflow rate from the Three Outlets was $865 \mathrm{~m}^{3} / \mathrm{s}$ in 2011. The number of days with mean daily flow rate higher than $970.81 \mathrm{~m}^{3} / \mathrm{s}$ was 91 , include time periods from 15 June to 16 August, 20 to

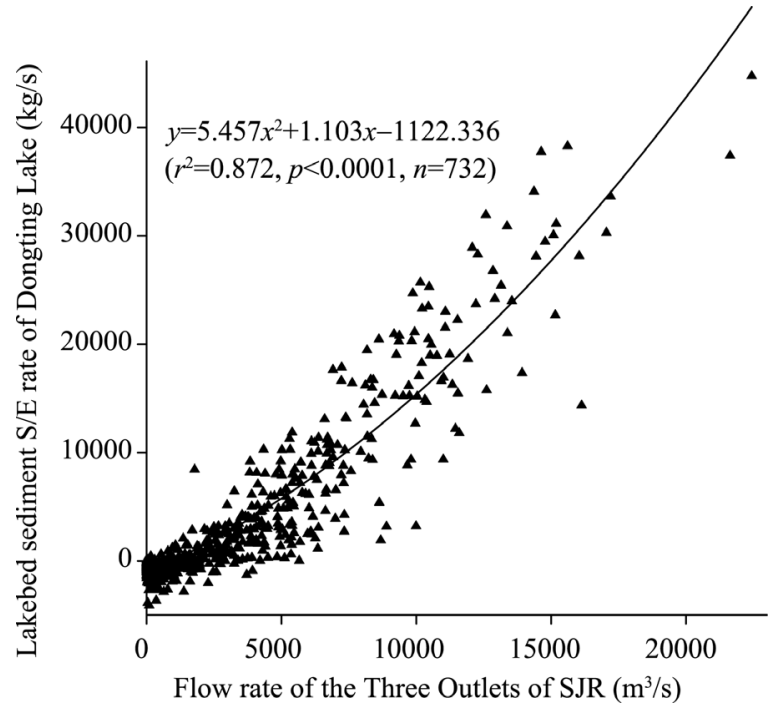

Figure 5 Relationship between inflow rate from the Three Outlets and the sediment S/E rate in the Dongting Lake 
28 September and 6 to 14 November. The flow rate during these time periods can be controlled under the threshold to maintain an erosion-dominant state in the lake. It is noteworthy that, apart from the inflow runoff and sediment discharge amount from the Three Outlets, the lakebed sediment S/E regimes can also be influenced by the hydrological conditions of the Four Rivers and the lake basin itself.

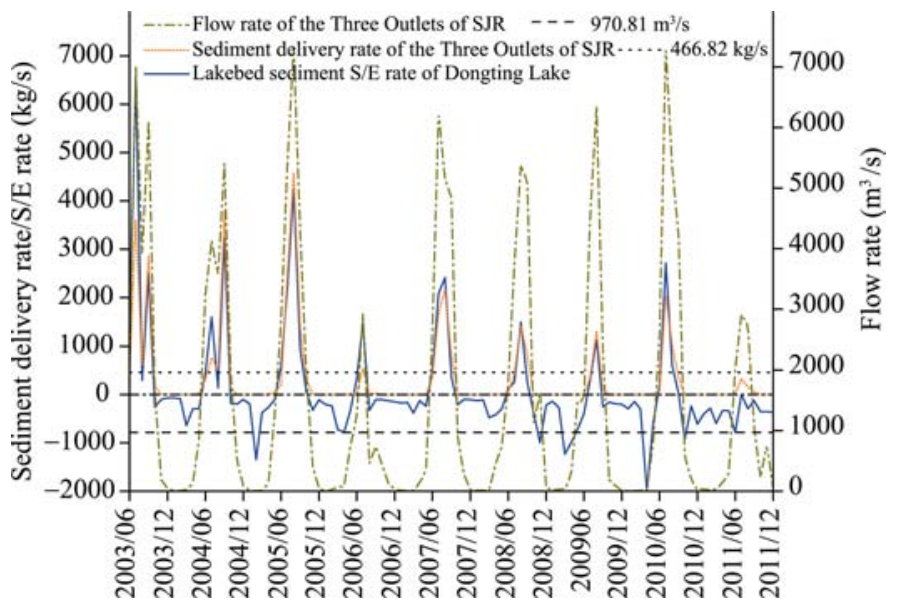

Figure 6 The variations of the flow rate and sediment delivery rate of the Three Outlets and the sediment S/E rate of the Dongting Lake under different impoundment phases of TGR

\section{Conclusions}

(1) The lakebed sediment S/E regimes transformed from a siltation-dominant to an erosion-dominant state during the impoundment Phase II. The intra-annual erosion-dominant state prolonged and the state dominated in pre-discharge, water-storage and water- supplement dispatch. The sediment deposition amount decreased dramatically from the impoundment Phase I to III.

(2) The thresholds for upstream hydrological condition regulation were relatively robust and straightforward. A vast amount of sediment was deposited in the Dongting Lake over the last six decades, and posed as impediments for water supply and transportation in the surrounding area.

(3) The thresholds were derived based on the assumption that no external condition, e.g. meteorological condition, in the watershed was changed after the operation of TGR compared to the period before the operation of TGR. In addition to the hydrological conditions at the upstream Three Outlets, the lakebed sediment S/E regimes were also influenced by the hydrological conditions at the lake outlet Chenglingji.

(4) The variation of hydrological conditions in the lake watershed is a combination effects of local climate change and anthropogenic activities. Further studies considering the lakebed sediment $\mathrm{S} / \mathrm{E}$ regimes mediated by the local climate change and human activities are therefore needed. 


\section{Acknowledgements}

The authors would like to thank Changjiang (Yangtze) Water Resources Committee and Hunan Hydro \& Power Institute for their help in providing the data presented in this work.

\section{References}

Chen Jin, 2010. Approach on drought defying operation of Three Gorges Reservoir. Journal of Yangtze River Scientific Research Institute, 27(5): 19-23. (in Chinese)

Dai Shibao, Yang Shilun, Zhao Huayun et al., 2005. Response of middle and lower reaches of Yangtze River to the initial operation stage of the Three Gorges Project. Journal of Sediment Research, (5): 35-39. (in Chinese)

Duan Wenzhong, Zheng Yahui, Liu Jianjun, 2001. Causes of water level rising in Chenglingji-Luoshan reach of Changjiang River. Journal of Hydraulic Engineering, (2): 29-34. (in Chinese)

Fu Renshou, Qi Meilan, Fang Hongwei et al., 2005. Sediment transport characteristics of Yangtze River in river section from Yichang to Hankou. Journal of Hydraulic Engineering, 36(1): 35-41. (in Chinese)

Han Qiwei, 1999. Changes of flood situation along the middle Yangtze River. Journal of Sediment Research, (5): 1-12. (in Chinese)

He Yong, Li Yitian, Wu Daoxi et al., 2006. Flow and sediment process versus river health. Journal of Hydraulic Engineering, 37(11): 1354-1359. (in Chinese)

Hu Chunhong, Zhang Zhihao, 2006. Evolution and control of estuary sandbar in Yellow River responding to variation of flow sediment condition. Journal of Hydraulic Engineering, 37(5): 511-517. (in Chinese)

Keown M P, Dardeau Jr. E A, Causey E M, 1986. Historic trends in the sediment flow regime of the Mississippi River. Water Resources Research, 22(11): 1555-1564.

Li Jingbao, Chang Jiang, Lv Dianqing et al., 2009. The hydrological effect between Jingjiang River and Dongting Lake during the initial period of Three Gorges Project operation. Acta Geographica Sinica, 64(11): 1342-1352. (in Chinese)

Li Jingbao, Wang Kelin, Qin Jianxin et al., 2005. The evolution of annual runoff and sediment in the Dongting Lake and their driving forces. Acta Geographica Sinica, 60(3): 503-510. (in Chinese)

Li Jingbao, Zhang Zhaoqing, Ou Chaomin et al., 2011. Responses of water regimes in Dongting Lake area under different dispatching modes during the running period of the Three Gorges Reservoir. Acta Geographica Sinica, 66(9): 1251-1260. (in Chinese)

Li Yitian, Guo Xiaohu, Tang Jinwu et al., 2009. Changes on runoff division from Jingjiang reach of the Yangtze River to Dongting Lake after the operation of TGR. Journal of Basic Science and Engineering, 17(1): 21-31. (in Chinese)

Lu Jinyou, Huang Yue, Gong Ping, 2006. Scouring and silting variation in middle and lower channel of the Yangtze River after TGP. Yangtze River, 37(9): 55-57. (in Chinese)

Lu Jinyou, Luo Hengkai, 1999. Preliminary analysis on variation of the relation between Yangtze River and Dongting Lake. Yangtze River, 30(4): 24-26. (in Chinese)

Sharaf El Din S H, 1977. Effect of the Aswan High Dam on the Nile flood and on the estuarine and coastal circulation pattern along the Mediterranean Egyptian coast. Limnology and Oceanography, 22(2): 194-207.

Walling D E, 2006. Human impact on land-ocean sediment transfer by the world's rivers. Geomorphology, 79(3/4): 192-216.

Wang Huilin, Liang Xing, 2003. Analysis on flood storage function of the Dongting Lake. Geography and Geo-Information Science, 19(3): 63-66. (in Chinese)

Xu Gui, Huang Yunxian, Li Xichun et al., 2004. Analysis on causes of water level rising at Chenglingji hydrological station of Changjiang River. Journal of Hydraulic Engineering, 35(8): 33-37. (in Chinese)

Zhang Zhen, Yang Shilun, Li Peng, 2010. Quantifying the influence of water impoundment Phases I and II of the Three Gorges Reservoir on downstream suspended sediment flux. Acta Geographica Sinica, 65(5): 623-631. (in Chinese)

Zhong Zhiyu, Hu Weizhong, 2008. On relation of river and lake. Yangtze River, 39(1): 20-23. (in Chinese) 